\section{Listeria monocytogenes persistence in ready-to-eat sausages and in processing plants}

\author{
Anna Mureddu, Roberta Mazza, \\ Federica Fois, Domenico Meloni, \\ Roberto Bacciu, Francesca Piras, \\ Rina Mazzette \\ Settore di Ispezione degli Alimenti \\ di Origine Animale, Dipartimento \\ di Medicina Veterinaria, Università \\ di Sassari, Italy
}

\section{Abstract}

Listeria monocytogenes is of major concern in the fermented meat products and is able to persist in their processing environments. The aim of the present work was to evaluate the virulence profile and the persistence capacity of $L$. monocytogenes strains isolated in Sardinian fermented sausages processing plants. Food (ground meat, sausages at the end of acidification and ripening stage) and environmental samples (a total of n. 385), collected from 4 meat processing plants located in Sardinia (Italy), were examined to detect $L$. monocytogenes presence. All the $L$. monocytogenes isolates were identified by polymerase chain reaction (PCR) method. A subset of strains was also characterised by multiplex PCR-based serogrouping, using the Imo0737, Imo1118, ORF2819 and ORF2110 genes. Three different multiplex PCRs were used to obtain the virulence profiles by the $r r n, h l y A$, actA, prfA, inlA, inlB, iap, plcA, plcB and $m p l$ marker genes. Furthermore, in vitro biofilm forming ability and resistance to disinfectants were carried out on microtiter plate. The overall prevalence was $31.5 \%$ in food, and $68.5 \%$ in environmental samples. The prevalent serotype resulted $1 / 2 \mathrm{c}(43 \%)$, followed by $1 / 2 \mathrm{a}$ (40\%), 4b (8.6\%), and 1/2b (8.6\%). The amplification products of the virulence genes were found in all the isolates with the following prevalence: $77.1 \%$ hlyA; $100 \%$ rrn; $100 \%$ prfA; 97.1\% iap; $65.7 \%$ inlB; $88.6 \%$ inlA; $100 \%$ plcA; $100 \% \mathrm{plcB}$ and $74.3 \% \mathrm{mpl}$. As for biofilm forming ability, $37.1 \%$ of the strains were positive and resulted weak producer, but all the isolates were sensible to disinfectants showing a reduction of $L$. monocytogenes growth after each incubation time. More appropriate technologies and application of measures of hygienic control should be implemented to prevent the $L$. monocytogenes growth and crosscontamination in salsiccia sarda processing plants.

\section{Introduction}

Listeria monocytogenes environmental persistent colonisation of ready-to-eat meat processing plants has been reported by several authors (Gram et al., 2007). The pathogen may survive in meat processing plants because its capability to multiply at low temperatures, adapt to disinfectants and adhere to various surfaces; furthermore, the biofilm forming ability is an important cause for such persistence (Arevalos-Sánchez et al., 2012; Cruz et al., 2012; Fonnesbech Vogel et al., 2001). It is not still clear if the persistence ability of $L$. monocytogenes is the result of adaption of certain subtypes, of poor cleaning and disinfection procedures or tolerance to some of the used disinfectants (Gram et al., 2007). Efficiency in cleaning and disinfection process is essential in preventing $L$. monocytogenes contamination of meat products. However, the presence of organic debris may inactivate the disinfectant, hence, the bacteria may be exposed to only sublethal concentrations and survives (Cruz et al., 2012).

In Sardinian fermented sausages and their facilities $L$. monocytogenes was detected (Mazzette et al., 2006), and serotypes involved in sporadic outbreaks of listeriosis $(1 / 2 \mathrm{a}, 1 / 2 \mathrm{~B}$, $1 / 2 \mathrm{c}$ and $4 \mathrm{~b}$ ) were reported. Longitudinal studies were previously carried out to evaluate the occurrence in this traditional ready to eat meat product, and to trace the sources and the routes in the processing plants. Moreover, the persistence ability of $L$. monocytogenes strains was demonstrated by molecular typing methods (Meloni et al., 2007, 2012a, 2012b).

The aim of the present work was to evaluate the virulence profile and the persistence capacity of $L$. monocytogenes strains isolated in Sardinian fermented sausages processing plants, during a short period of time, and to study the effectiveness of disinfecting products against the strains, in order to define more appropriate control strategies of the environment contamination.

\section{Materials and Methods}

A total of n. 385 samples taken from 4 Sardinian sausage processing plants, from 2 production batches, were examined. The samples were from: ground meat, sausages at the end of acidification and ripening period (n. 165), and surfaces (n. 220) with and without contact with meat.

Detection and enumeration of $L$. monocytogenes were carried out by using the ISO 112901:1996 and 11290-2:1998 (ISO, 1996, 1998) protocols, respectively. All the isolates (n. 173) had been previously identified and characterised by
Correspondence: Rina Mazzette, Settore di Ispezione degli Alimenti di Origine Animale, Dipartimento di Medicina Veterinaria, Università di Sassari, via Vienna 2, 07100 Sassari. Tel. +39.079.229452 - Fax: +39.079.229458. E-mail: rmazzett@uniss.it

Key words: Listeria monocytogenes, Salsiccia sarda, Biofilm, Disinfectant resistance.

Conflict of interests: the authors declare no potential conflict of interests.

Received for publication: 20 May 2013

Revision received: 22 August 2013.

Accepted for publication: 29 August 2013.

This work is licensed under a Creative Commons Attribution 3.0 License (by-nc 3.0)

CC Copyright A. Mureddu et al., 2014

Licensee PAGEPress, Italy

Italian Journal of Food Safety 2014; 3:1697

doi:10.4081/ijfs.2014.1697

molecular tests (Mureddu et al., 2011). Among these, a subset of n. $35 \mathrm{~L}$. monocytogenes strains, representative of the positive samples, was selected from various sources. The different plants, and, within these, the environmental and food samples, and the sampling sessions (I, II), were considered. The subset of $L$. monocytogenes strains were submitted to the biomolecular and phenotypic investigations described in the following.

\section{Serotyping and molecular}

pathogenic profile

Serotyping was performed as described by Doumith et al. (2004). The marker genes selected for the multiplex polymerase chain reaction (PCR) assay were $I m o 0737$, Imo1118, ORF2819 and ORF2110. Moreover, three different multiplex PCRs were performed in order to detect ten virulence-associated genes using the protocols of Border et al. (1990) and Jaradat et al. (2002), with some modifications. Multiplex PCR 1 amplified the rrn, hlyA, actA and prfA genes, multiplex PCR 2 the inlA, inlB and iap genes and multiplex PCR 3 the plcA, $p l c B$ and $m p l$ genes. The GoTaq Hot Start Master Mix (Promega Corp., Madison, WI, USA) was used for amplification of the target DNA fragments, as indicated in the manufacturer's instructions. Primers sequences used are set in Table 1.

\section{In vitro biofilm forming ability and resistance to disinfectants}

The quantitative in vitro biofilm forming ability (BFA) was carried out on sterile 96 -well polystyrene microtiter plates, using the method described by Stepanovic et al. (2004), modified. Each strain was inoculated into two 
different microplates in order to assess biofilm formation after incubation at $30^{\circ} \mathrm{C}$ for 20 and $40 \mathrm{~h}$. The optical density (OD) was evaluated using a Sunrise RC absorbance reader (Tecan, Maennedorf, Switzerland). In relation to the OD values, the strains of $L$. monocytogenes have been classified into 4 categories (Meloni et al., 2012a, 2012b).

A qualitative in vitro evaluation of the resistance to disinfectants (chlore and quaternary ammonium compounds), commonly used in the plants included in this survey, was performed, according to Fox et al. (2004) method, modified. For each strain, $5 \mathrm{~mL}$ of the overnight $L$. monocytogenes culture $\left(37^{\circ} \mathrm{C}\right)$ on TSB was obtained [approximately $10^{8}$ colony forming units (CFU) $/ \mathrm{mL}^{-1}$ ]. The day of the experiment, starting from the disinfectant concentration used in each plant (stock concentration), two serial dilutions $\left(10^{-1}, 10^{-2}\right)$ were prepared. A sterile microtiter ninety-six well plate, containing $150 \mu \mathrm{L}$ of the disinfectants (stock, $10^{-1}, 10^{-2}$ concentration) was inoculated with $10 \mu \mathrm{L}$ of a $10^{-1}, 10^{-2}, 10^{-3}$ and $10^{-4}$ fold diluted overnight culture. A positive and reagent control (without inoculum) were also used. Each plate was then placed in a Sunrise RC absorbance reader (Tecan,
Mannedorf, Switzerland), and reduction of $L$. monocytogenes concentration was monitored by measuring the $0 \mathrm{D}$ at $620 \mathrm{~nm}$, after four incubation time, for 0 up to 3 days (72 h).

\section{Results}

L. monocytogenes prevalence resulted as follows: $31.5 \%$ in food samples, $17.4 \%$ in surface in contact, and $11.4 \%$ in surface not in contacts with meat. In particular, during the process, prevalence increased until the end of the acidification stage $(60 \%)$, then decreased in the ripening period (20\% in finished products), but the contamination levels were always below $100 \mathrm{CFU} / \mathrm{g}$, as recommended in EC Reg. 2073/2005 (European Commission, 2005) for the food safety criteria in the RTE foods.

\section{Serotyping and molecular pathogenic profile}

The 1/2c was the prevalent serotype (43\%) in all the plants, except $A$, followed by $1 / 2 \mathrm{a}$ (40\%), that was detected in all the samples (surfaces and food), 1/2b (8.6\%) and 4b (8.6\%) The molecular analysis of the virulence factors
(Table 2) showed that the amplification products of the analysed virulence genes were found in all the Listeria monocytogenes strains, with the following prevalence: $77.1 \%$ hlyA; $100 \%$ rrn; 100\% prfA; $97.1 \%$ iap; $65.7 \%$ inlB; $88.6 \%$ inlA; $100 \%$ plcA; $100 \%$ plcB and $74.3 \%$ $m p l$ (Table 2). Primers used for the detection of $a c t A$ allowed the amplification of two different products (268 and $385 \mathrm{bp}$ ), showing a polymorphism for this gene. The $268 \mathrm{bp}$ amplification band was detected in only $8.6 \%$ of isolates, while the $68.6 \%$ showed a 385 bp fragment.

\section{In vitro biofilm forming ability and resistance to disinfectants}

The $37.1 \%$ of the strains resulted able to in vitro biofilm formation after $40 \mathrm{~h}$ of incubation. All these strains belonged to the weak producer (WP) category, while none showed moderate (MP) or strong (SP) ability. The $50 \%$ of the strains able to produce biofilm belonged to serotype $1 / 2 \mathrm{c}$, the $41.6 \%$ to $1 / 2 \mathrm{a}$ and the $8.3 \%$ to $4 \mathrm{~b}$.

The results of the in vitro evaluation of the resistance to disinfectants is expressed in Table 3 as a reduction (+) and not reduction $(-)$ of $L$. monocytogenes growth, on the basis of the $O D$ value at $620 \mathrm{~nm}$. All the strains showed

Table 1. Sequence, concentration and size of the primers used to detect virulence genes.

\begin{tabular}{|c|c|c|c|c|c|}
\hline PCR & Primers & & Sequence $\left(5^{\prime}-3^{\prime}\right)$ & Primer concentration ( $\mu \mathrm{M})$ & Product size (bp) \\
\hline \multirow[t]{8}{*}{1} & \multirow[t]{2}{*}{$r n$} & $\mathrm{~F}$ & CAGCAGCCGCGGTAATAC & \multirow[t]{8}{*}{0.9} & 938 \\
\hline & & $\mathrm{R}$ & CTCCATAAAGGTGACCCT & & \\
\hline & \multirow[t]{2}{*}{ hlyA } & $\mathrm{F}$ & CCTAAGACGCCAATCGAA & & \multirow[t]{2}{*}{702} \\
\hline & & $\mathrm{R}$ & AAGCGCTTGCAACTGCTC & & \\
\hline & \multirow[t]{2}{*}{$a c t A$} & $\mathrm{~F}$ & GACGAAAATCCCGAAGTGAA & & \multirow[t]{2}{*}{$268 / 385$} \\
\hline & & $\mathrm{R}$ & CTAGCGAAGGTGCTGTTTCC & & \\
\hline & \multirow[t]{2}{*}{ prfa } & $\mathrm{F}$ & CTGTTGGAGCTCTTCTTGGTGAAGCAATCG & & \multirow[t]{2}{*}{1060} \\
\hline & & $\mathrm{R}$ & AGCAACCTCGGAACCATATACTAACTC & & \\
\hline \multirow[t]{6}{*}{2} & \multirow[t]{2}{*}{ inlA } & $\mathrm{F}$ & СCTAGCAGGTCTAACCGCAC & \multirow[t]{6}{*}{0.9} & 255 \\
\hline & & $\mathrm{R}$ & TCGCTAATTTGGTTATGCCC & & \\
\hline & \multirow[t]{2}{*}{ inlB } & $\mathrm{F}$ & AAAGCACGATTTCATGGGAG & & \multirow[t]{2}{*}{146} \\
\hline & & $\mathrm{R}$ & ACATAGCCTTGTTTGGTCGG & & \\
\hline & \multirow[t]{2}{*}{ iap } & $\mathrm{F}$ & ACAAGCTGCACCTGTTGCAG & & \multirow[t]{2}{*}{131} \\
\hline & & $\mathrm{R}$ & TGACAGCGTGTGTAGTAGCA & & \\
\hline \multirow[t]{6}{*}{3} & \multirow[t]{2}{*}{ plcA } & $\mathrm{F}$ & CGAGCAAAACAGCAACGATA & \multirow[t]{6}{*}{0.9} & 129 \\
\hline & & $\mathrm{R}$ & CCGCGGACATCTTTTAATGT & & \\
\hline & \multirow[t]{2}{*}{$p l c B$} & $\mathrm{~F}$ & GGGAAATTTGACACAGCGTT & & \multirow[t]{2}{*}{261} \\
\hline & & $\mathrm{R}$ & ATTTTCGGGTAGTCCGCTTT & & \\
\hline & \multirow[t]{2}{*}{ mpl } & $\mathrm{F}$ & TTGTTCTGGAATTGAGGATG & & \multirow[t]{2}{*}{502} \\
\hline & & $\mathrm{R}$ & TTAAAAAGGAGCGGTGAAAT & & \\
\hline
\end{tabular}

PCR, polymerase chain reaction.

Table 2. Virulence genes prevalence (\%) of the L. monocytogenes strains (n. 35) in relation to the plants.

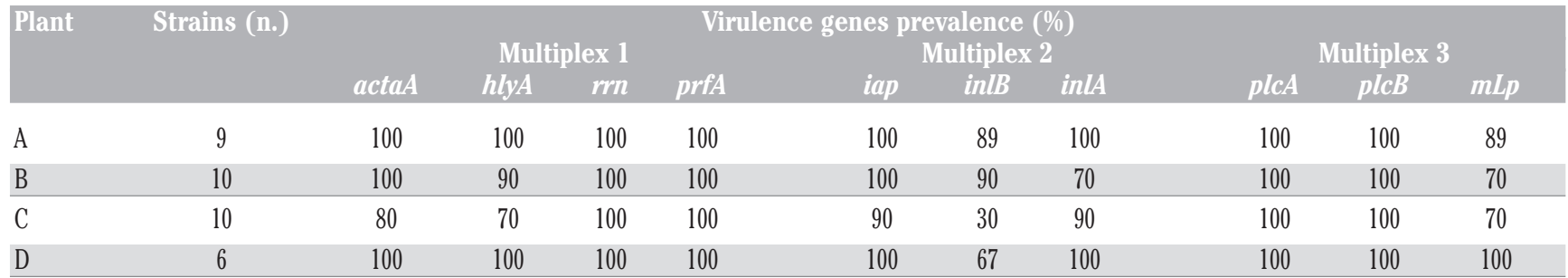


a reduction of $L$. monocytogenes growth after each incubation time (24, 48 and $72 \mathrm{~h}$ ). The $L$. monocytogenes isolates were from environmental (n. 16) and products (n. 19) samples. Most of the strains belonged to $1 / 2 \mathrm{c}$ (n. 15) and $1 / 2 \mathrm{a}$ (n. 14) serogroups, while only 6 to $1 / 2 b$ (n. 3) and 4b (n. 3).

In Table 4 the results of serotyping, biofilm forming ability and resistance to disinfectants of $L$. monocytogenes strains are summarised in relation to the plant, batches and source. In plant A, L. monocytogenes was detected both in food (except for the sausage at the end of ripening) and in environmental samples; all the isolates belonged to $1 / 2 \mathrm{~b}$ and $1 / 2 \mathrm{c}$ serovars, and resulted NP biofilm and sensitive to disinfectants. In plant $\mathrm{B}$, the strains were also isolated in food and in environmental sites, from both production batches. The $4 \mathrm{~b}$ serovar profile (n. 1 strain) was isolated only in this plant from GM samples. Five strains isolated from food and environmental samples belonged to 1/2a resulted NP, while two strains isolated from the SWC were WP. In plant C, two strains from GM samples (batch I), belonging to $1 / 2 \mathrm{a}$ and 1/2c serovars, were WP; WP strains belonging to $1 / 2$ a serotype were also detected in AS, and both serotypes in surface in contact samples. The plant $\mathrm{C}$ had the higher production capacity. In plant D, four strains (batch I) belonged to $1 / 2 \mathrm{c}$ serovars, and isolated from food samples, were WP, in particular three were from GM and one from AS.

\section{Discussion and Conclusions}

The results underline the overall presence of $L$. monocytogenes in different samples of Sardinian fermented sausages and environmental niches. In addition to the primary contamination by raw meat, cross contamination by surfaces in contact with meat should be considered as source of $L$. monocytogenes. An inhomogeneous decrease of the pathogen prevalence was observed in ripened sausages (29.1\%), highlighting, in agreement with other authors (Thévenot et al., 2005), the presence of strains able to survive during sausages fermentation. Even if the contamination level was always low, the presence of $L$. monocytogenes in the ripened products confirms that the hurdles of microbial growth (mainly the $\mathrm{a}_{\mathrm{w}}$ decrease) should properly be applied during the ripening in order to prevent the $L$. monocytogenes growth.

The evaluation of biofilm production showed a low short-time persistence (3-4 months) capacity of the $L$. monocytogenes strains included in the study. Most of the isolates were unable, and only $37.1 \%$ showed a weak in vitro ability to biofilm formation, in particular strains from food (61.5\%) and, less frequently, from surfaces with (trolleys) and without (floor drains) contact with meat. Harborage niches, as the floor drains, can be critical sites for the processing plant environment and food product contamination (Tompkin, 2002). Decontaminating floor drains is essential to prevent the $L$. monocytogenes biofilm formation, and a potential resistance against available disinfectants and treatments (Gram et al., 2007). About this topics, disinfectant resistance has been studied among groups of persistent and non persistent strains, but no clear link between persistence and increased disinfectant resistance was seen (Kastbjerg et al., 2009; Holah et al., 2002). Some authors showed that a reorganisation or regeneration mechanism of the lipidic membrane may occur (Fox et al., 2011), and others highlight that no strains show unique properties that lead to persistence, but harborage sites in food industry premises and equipment can persist (Carpentier et al., 2011). In our study all the strains resulted sensitive to all the tested disinfectants. Other authors had previously reported that the recommended concentrations of commercial sanitisers are higher

Table 3. In vitro qualitative reduction evaluation of $L$. monocytogenes by disinfectant products.

\begin{tabular}{|c|c|c|c|c|}
\hline Disinfectant & Plant & $\begin{array}{c}\text { Concentration } \\
(\%)\end{array}$ & $\begin{array}{c}\text { Temperature } \\
\left({ }^{\circ} \mathrm{C}\right)\end{array}$ & $\begin{array}{l}\text { Incubation time } \\
\text { (h) }\end{array}$ \\
\hline Chlore substances & $1-5 \%$ & 37 & $\begin{array}{l}24 \\
48 \\
72\end{array}$ & $\begin{array}{l}(+) \\
(+) \\
(+)\end{array}$ \\
\hline $\begin{array}{l}\text { Quaternary ammonium } \\
\text { compounds }\end{array}$ & n $2 \%$ & 37 & $\begin{array}{l}24 \\
48 \\
72\end{array}$ & $\begin{array}{l}(+) \\
(+) \\
(+)\end{array}$ \\
\hline
\end{tabular}

Table 4. Serotype, biofilm forming ability and resistance to disinfectants of L. monocytogenes strains, in relation to the plants, batches and sources.

\begin{tabular}{|c|c|c|c|c|c|}
\hline Plant & Source & $\begin{array}{l}\text { Batch } \\
\text { I II }\end{array}$ & Serotype & BFA & $\begin{array}{l}\text { Disinfectant } \\
\text { resistance }\end{array}$ \\
\hline A & $\begin{array}{c}\text { GM } \\
\text { AS } \\
\text { RS } \\
\text { SC } \\
\text { SWC }\end{array}$ & $\begin{array}{l}. \\
. \\
. \\
.\end{array}$ & $\begin{array}{l}1 / 2 \mathrm{~b}(1) \\
1 / 2 \mathrm{~b}(2) \\
1 / 2 \mathrm{c}(1) \\
1 / 2 \mathrm{c}(1) \\
1 / 2 \mathrm{c}(3) \\
1 / 2 \mathrm{c}(1)\end{array}$ & $\begin{array}{l}\text { NP } \\
\text { NP } \\
\text { NP } \\
\text { NP } \\
\text { NP } \\
\text { NP }\end{array}$ & $\begin{array}{l}(-) \\
(-) \\
(-) \\
(-) \\
(-) \\
(-)\end{array}$ \\
\hline
\end{tabular}

Total n. 9

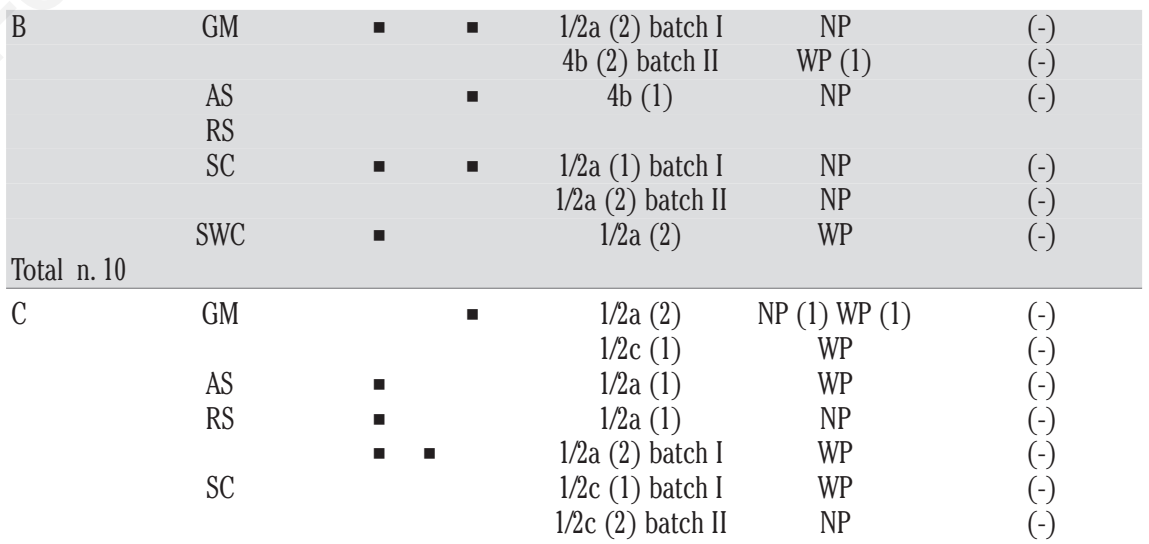

Total n. 10

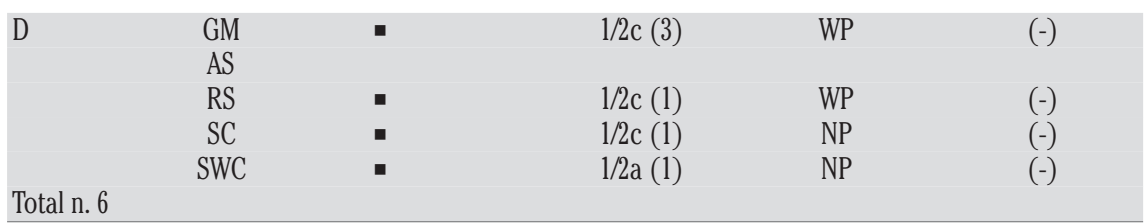

BFA, biofilm forming ability; GM, ground meat; AS, sausage at the end of acidification; $\mathrm{RS}$, sausage at the end of ripening; $\mathrm{SC}$, surface in contact; SWC, surface without contact. 
than required (Cruz et al., 2012). Although the results are preliminary and related to a small number of strains, the microtiter plate assay seems to be useful as an indirect way of assess the disinfectant resistence of $L$. monocytogenes strains.

The molecular findings revealed the presence of all the considered virulence genes, suggesting that all the isolates could be potentially dangerous for public health. No correlation between serotype and virulence profile was observed, neither between serotypes and plants. This is not in agreement with previous studies, where some $L$. monocytogenes serotypes appeared to be unique for a processing plant and should be considered as plantspecific (Fugett et al., 2007).

The fermented pork meat RTE products, as dry and semi-dry sausages, have been rarely implicated in food-borne disease. However, more risks should be linked to the consumption of these products, mainly in the manufacturing of traditional products, where an empirical application of the hurdles technology and lack of measures of hygienic control often occurs.

\section{References}

Arevalos-Sánchez M, Regalado C, Martin SE, Domínguez-Domínguez J, GarcíaAlmendárez BE, 2012. Effect of neutral electrolyzed water and nisin on Listeria monocytogenes biofilms and on listeriolys in 0 activity. Food Control 24:116-22.

Border PM, Howard JJ, Plastow GS, Siggens KW, 1990. Detection of Listeria species and Listeria monocytogenes using polymerase chain reaction. Lett Appl Microbiol 11:158-62.

Carpentier B, Cerf 0, 2011. Review. Persistence of Listeria monocytogenes in food industry equipment and premises. Int J Food Microbiol 145:1-8.

Cruz CD, Fletcher GC, 2012. Assessing manufacturers' recommended concentrations of commercial sanitizers on inactivation of Listeria monocytogenes. Food Control 26:194-9.

Doumith M, Buchrieser C, Glaser P, Jacquet C, Martin P, 2004. Differentiation of the major Listeria monocytogenes serovars by multiplex PCR. J Clin Microbiol 42:381922.
European Commission, 2005. Regulation of the European Parliament and of the Council of 15 November 2005 on microbiological criteria for foodstuffs, 2073/2005/EC. In: Official Journal, L 338, $22 / 12 / 2002$.

Fonnesbech Vogel B, Huss HH, Ojeniyi B, Ahrens P, Gram L, 2001. Elucidation of Listeria monocytogenes contamination routes in cold-smoked salmon processing plants detected by DNA-based typing methods. Appl Environ Microb 67:2586-95.

Fox EM, Nola L, Jordan K, 2011. Physiological and transcriptional characterization of persistent and nonpersistent Listeria monocytogenes isolates. Appl Environ Microb 18:6559-69.

Fugett EB, Schoonmaker-Bopp D, Dumas NB, Corby J, Wiedmann M, 2007. Pulsed-Field Gel Electrophoresis (PFGE) analysis of temporally matched Listeria monocytogenes isolates from human clinical cases, foods, ruminant farms, and urban and natural environments reveals source-associated as well as widely distributed PFGE types. J Clin Microbiol 45:865-73.

Gram L, Bagge-Ravne D, Yin Ng Y, Gymoese P, Fonnesbech Vogel B, 2007. Influence of food soiling matrix on cleaning and disinfection efficiency on surface attached Listeria monocytogenes. Food control 18:1165-71.

Holah JT, Taylor JH, Dawson DJ, Hall KE, 2002. Biocide use in the food industry and the disinfectant resistance of persistent strains of Listeria monocytogenes and Escherichia coli. J Appl Microbiol 92:111S$20 \mathrm{~S}$.

ISO, 1996. Microbiology of food and animal feeding stuffs. Horizontal method for the detection and enumeration of Listeria monocytogenes. Part 1: detection method. ISO norm 11290-1:1996. International Organization for Standardization Publ., Geneva.

ISO, 1998. Microbiology of food and animal feeding stuffs. Horizontal method for the detection and enumeration of Listeria monocytogenes. Part 2: enumeration method. IS0 norm 11290-2. International Organization for Standardization Publ., Geneva.

Jaradat ZW, Schutze GE, Bhunia AK, 2002. Genetic homogeneity among Listeria monocytogenes strains from infected patients and meat products from two geo- graphic locations determined by phenotyping, ribotyping and PCR analysis of virulence genes. Int J Food Microbiol 76:1-10.

Kastbjerg VG, Halberg Larsen M, Gram L, Ingmer H, 2009. Influence of sublethal concentrations of common disinfectants on expression of virulence genes in Listeria monocytogenes. Appl Environ Microb 76:303-9.

Mazzette R, Meloni D, Mureddu A, Lepori L, Cosseddu AM, 2006. Prevalence and molecular typing of Listeria monocytogenes in ready to eat meat products and in the processing plants. In: Proceedings of the 20th International ICFMH Symposium Food safety and food biotechnology: diversity and global impact, Bologna, Italy, Aug 29-Sept 2 2006, p. 184.

Meloni D, Mazza R, Piras F, Lamon S, Consolati SG, Mureddu A, Mazzette R, 2012a. The biofilm formation ability of Listeria monocytogenes isolated from meat, poultry, fish and processing plant environments is related to serotype and pathogenic profile of the strains. Vet Sci Dev 2:e12.

Meloni D, Mureddu A, Piras F, Mazzette R, 2007. Application of PFGE typing to trace the routes of Listeria monocytogenes contamination in "salsiccia sarda" processing plants: preliminary results. In: Meat safety: from abattoir to consumer. Proceedings of the International Symposium, Febr 14-15 2007, Valencia, Spain, pp. 70-4.

Meloni D, Piras F, Mureddu A, Mazza R, Nucera D, Mazzette R, 2012b. Sources of Listeria monocytogenes contamination in traditional fermented sausages processing plants in Italy. Ital J Food Sci 3:214-22.

Mureddu A, Conter M, Meloni D, Piras F, Ianieri A, Mazzette R, 2011. Molecular characterization of L. monocytogenes isolated from ready-to-eat seafood in Italy. Ital J Food Sci 23:106-17.

Stepanovic S, Cirkovic I, Ranin L, SvabicVlahovic M, 2004. Biofilm formation by Salmonella spp. and Listeria monocytogenes on plastic surfaces. Lett Appl Microbiol 38:428-32.

Thévenot D, Delignette-Muller ML, Christieans S, Vernozy-Rozand C, 2005. Prevalence of Listeria monocytogenes in 13 dried sausage processing plants and their products. Int J Food Microbiol 102: 85-94.

Tompkin RB, 2002. Control of Listeria monocytogenes in the food-processing environment. J Food Protect 65:709-25. 